\title{
An Alkaline Solution of Potassium Chromate as a Transmittancy Standard in the Ultraviolet
}

\author{
Geraldine W. Haupt
}

\begin{abstract}
The need for a means of testing the reliability of the photometric scale of spectrophotometers in the ultraviolet region (where glasses are unsuitable) has led to the study of an aqueous solution of potassium chromate having the composition $0.0400 \mathrm{~g} /$ liter of $\mathrm{K}_{2} \mathrm{CrO}_{4}$ in $0.05 \mathrm{~N} \mathrm{KOH}$. Based on extensive measurements, using photographic, photoelectric, and visual spectrophotometry, standard values of spectral transmittancy have been determined for 1.000 and $2.000 \mathrm{~cm}$ of solution at $25^{\circ} \mathrm{C}$ from 220 to $500 \mathrm{~m} \mu$. These values have been tabulated along with derived values of absorbancy, molar absorbancy index $a_{M}$, and $\log _{10} a_{M}$. The latter values have been compared graphically with those of other observers. Changes in spectral transmittancy with changes in temperature have been determined. The work has also included a study of the effects due to the container bottle and to age of solutions over periods up to 8 years, and a comparison of results obtained with the solution prepared either from $\mathrm{K}_{2} \mathrm{CrO}_{4}$ or from $\mathrm{K}_{2} \mathrm{Cr}_{2} \mathrm{O}_{7}$ as one of the reagents.
\end{abstract}

\section{Introduction}

A means of testing the reliability of the photometric scale of spectrophotometers in the ultraviolet region has been in demand for a number of years. With the introduction of commercial photoelectric spectrophotometers for the ultraviolet in 1940, the demand increased considerably.

Although glass filter standards of spectral transmittance $[1,2]^{1}$ have proved to be a very satisfactory and valuable means of testing the reliability of the photometric scale of spectrophotometers in the visible region, they are in general unsatisfactory in the ultraviolet. Not only do all but a few special glasses absorb completely below $290 \mathrm{~m} \mu$, but, in addition, the ultraviolet spectral transmittances of many glasses change on exposure to strong ultraviolet radiant flux $[2,3,4]$. In these respects solutions in cells with quartz end plates are found to be superior to glasses for use in the ultraviolet. In addition, solutions are reproducible and can be prepared in the laboratory from specifications with relatively small time and cost. Various solutions have been studied or recommended ${ }^{23}$ for this purpose. Preeminent among these is an aqueous solution of potassium chromate, $\mathrm{K}_{2} \mathrm{CrO}_{4}(0.04 \mathrm{~g} /$ /liter $)$ in $0.05 \mathrm{~N} \mathrm{KOH}$. This has alternate regions of high transmission and absorption in the ultraviolet, and this one solution in 1- and 2-cm thicknesses covers the transmittancy scale from about 0.90 to about 0.01 (0.046 to 2.0 in absorbancy). Several investigators have previously worked with this solution, and from the information available in 1940 this appeared to be one of the best for the purpose. It was accordingly selected for calibration. ${ }^{4}$

\footnotetext{
Figures in brackets indicate the literature references at the end of this paper.

1 Figures in brackets indicate the literature references at the end of this paper.
2 For example, Brode $[5$, p. 200] lists potassium chromate, azobenzene, and potassium nitrate as solutions that can be accurately prepared as standards for the calibration of spectrophotometers.

${ }^{3}$ Photoelectric Spectrophotometry Group of England has recently conducted a collaborative test on the use of $\mathrm{K}_{2} \mathrm{Cr}_{2} \mathrm{O}_{7}$ [6]

4 Solutions can, of course, also be used in the visible region. In fact, the aqueous solutions of copper sulfate and cobalt ammonium sulfate used in the Davis-Gibson filters $[7,8,9,10]$ have been recommended for that purpose.
}

To make the solution most useful as a calibration standard of spectral transmittancy in the ultraviolet, information should be available regarding its permanence, or stability, under specified conditions (including the effects of the container bottles on the spectral transmittancy) and regarding any change in its spectral transmittancy with temperature over the range of room temperatures to be expected. Such data have accordingly been obtained.

This investigation was started in 1940 and discontinued in 1943 because of the war. It was resumed in 1948 , and preliminary data have been published $[8,9,10]$. The present paper describes the work leading up to the determination of these preliminary values, based solely on the measurements made in $1940-43$, and describes the recent work on new solutions with a new instrument, on the basis of which the final values were derived as herein published.

\section{Preparation of Solutions}

All the potassium chromate solutions studied were prepared in the Bureau's Chemistry Division by W. Stanley Clabaugh. The solutions are of two general types (A) those prepared bv dissolving the salt in dilute solution of $\mathrm{KOH}$, and (B) those prepared by dissolving the salt in distilled water.

The type (A), or alkaline, solutions were prepared as follows:

$\left(\mathrm{A}_{1}\right)$ : A solution of $\mathrm{K}_{2} \mathrm{CrO}_{4}$ stock material, reagent grade, $0.0400 \mathrm{~g} /$ liter, in $0.05 \mathrm{~N} \mathrm{KOH}$ (solution of potassium hydroxide prepared by dissolving $3.3 \mathrm{~g}$ of potassium hydroxide sticks $(85 \% \mathrm{KOH})$ of reagent

These solutions have their limitations for use as calibration standards both in the shortwave end of the visible region and in the ultraviolet region. In the visible, neither of them has sufficient absorption in the violet to be of much value for the purpose. In the ultraviolet, the copper sulfate solution varies rather rapidly from high transparency at wavelengths above $330 \mathrm{~m} \mu$ to high absorption at wavelengths below $270 \mathrm{~m} \mu$ and thus has no general utility over the whole at wavelengths below $270 \mathrm{~m} \mu$ and thus has no general utility over the whole
region. The cobalt ammonium sulfate solution used in the Davis-Gibson filters region. The cobalt ammonium sulfate solution used in the Davis-Gibson filters
[7] has too high transparency between 230 and $400 \mathrm{~m} \mu$ to be of much value as a spectrophotometric standard. Solutions prepared at 10 times this concentration were found (unpublished data) to be unstable with time throughout the ultraviolet and were thus considered undesirable for use as spectrophotometric calibration standards. 
quality in sufficient distilled water to make 1 liter).

$\left(\mathrm{A}_{2}\right)$ : A solution of $\mathrm{K}_{2} \mathrm{CrO}_{4}$ of the same concentration and alkalinity as $\left(A_{1}\right)$ but prepared from $0.0303 \mathrm{~g}$ of $\mathrm{K}_{2} \mathrm{Cr}_{2} \mathrm{O}_{7}{ }^{5}$, which, when converted gave $0.0400 \mathrm{~g}$ of $\mathrm{K}_{2} \mathrm{CrO}_{4}$ liter. This follows from the reaction $\mathrm{K}_{2} \mathrm{Cr}_{2} \mathrm{O}_{7}+2 \mathrm{KOH}=2 \mathrm{~K}_{2} \mathrm{CrO}_{4}+\mathrm{H}_{2} \mathrm{O}$.

The purpose of dissolving the potassium chromate in dilute solutions of $\mathrm{KOH}$ was to prevent any dichromate from forming. In $\mathrm{A}_{2}$ a potassium chromate solution was prepared by means of a different material, potassium dichromate. This solution was prepared to determine whether the spectrophotometric data from $A_{1}$ and $A_{2}$ would be identical. Since they were found to be identical, there is a distinct advantage in using potassium dichromate as one of the reagents rather than potassium chromate, because in stock material potassium dichromate exists in a purer state. A special sample of potassium chromate that had been recrystallized four times was used in the preparation of one of the B, or neutral, solutions with the view to studying the effect of the purity of the potassium chromate.

The solutions prepared in 1940, 1942, and again in 1949 were stored in liter bottles of the ordinary storeroom glass type with glass stoppers. For further study of the effect of storage, half of the 1940 alkaline solution prepared from $\mathrm{K}_{2} \mathrm{CrO}_{4}$ and half of the 1940 neutral solutions were stored in similar bottles lined with ceresin. The tips of the rubber stoppers used were also covered with ceresin. Also half of the alkaline solutions prepared by methods $A_{1}$ and $A_{2}$ in 1949 were stored in alkali-resistant glass (Corning glass 728).

None of the solutions was exposed to light except when actually in use to fill the cells for their measurement. No solution was ever poured out of its bottle. In filling the cells a pipette was used to draw off the solution. Where flaking occurred, the sediment thus remained on the bottom of the bottle. Each cell containing solution was measured relative to a similar cell containing distilled water.

The alkaline solutions are those from which the standard set of spectral transmittancies given in table 1 were obtained. Although both alkaline and neutral solutions were prepared originally for the purpose of establishing standard spectral transmittancy data, the neutral solutions were finally not used for that purpose. However, as the neutral solutions have been studied over a period of 8 years, a summary of the results on these is included in section 8 .

\section{Methods of Measurement}

The solutions were measured on five instruments by three different methods. One instrument operates by a photographic method, primarily for the ultraviolet region, but extending also into the violet and blue; one by a visual method; and three by photoelectric, one of these being for the visible range only.

${ }_{5}$ Standard Sample $\mathrm{K}_{2} \mathrm{Cr}_{2} \mathrm{O}_{7}$, No. 136 , may now be obtained from the National Bureau of Standards. At the time these solutions were prepared, the chemical used all conformed to ACS specification.

\subsection{Photographic Method}

The photographic data were obtained by means of the Hilger sector photometer with the Fuess quartz spectrograph $[11,12,13]$.

The equivalent slit widths for an $0.2-\mathrm{mm}$ slit, which was used throughout all the exposures, are

\begin{tabular}{|c|c|c|}
\hline \multirow{2}{*}{ Wavelength } & \multicolumn{2}{|c|}{ Slit widths } \\
\cline { 2 - 3 } & & \\
\cline { 2 - 3 }$m \mu$ & $m m$ & $m \mu$ \\
400 & 0.2 & 0.6 \\
310 & .2 & .25 \\
260 & .2 & .13 \\
220 & .2 & .08 \\
& & \\
\hline
\end{tabular}

On each plate exposures were made of at least two aluminum spark spectra for wavelength calibration purposes. A calibration curve was used to translate scalar values, which were read at the density matchpoints, into wavelengths. Both $1.000-$ and $4.000-\mathrm{cm}$ cells were used with the Hilger instrument.

\subsection{Visual Method}

The König-Martens spectrophotometer [13, 14] is a visual instrument. The slit widths used on this instrument are varied, depending upon the wavelength and the spectral characteristics of the sample being measured. With an incandescent source the equivalent slit widths in millimicrons used for two wavelengths and for two settings of the slits are given below:

\begin{tabular}{|c|c|c|}
\hline \hline \multirow{2}{*}{ Wavelength } & \multicolumn{2}{|c|}{ Slit widths } \\
\cline { 2 - 3 }$m \mu$ & $m m$ & $m \mu$ \\
400 & 0.5 & 2.7 \\
500 & .2 & 2.7 \\
\hline
\end{tabular}

The mercury arc, also available for use on this instrument, enables transmittancy measurements to be made that are not subject to possible wavelength or slit-width errors.

Two cell lengths were used with this instrument, namely, 4.000 and $10.000 \mathrm{~cm}$.

\subsection{Photoelectric Method}

\section{a. Brackett Quartz Double Monochromator and Auxiliary Equipment [15]}

The source of illumination used was a special incandescent lamp, with a quartz window, which operated on a 120 -volt, 45-ampere battery. The monochromator has three slit systems. The exit slit next to the photoelectric tube was kept at a constant mechanical width for nearly all the measurements, and the other two were varied concurrently. Any stray energy that passes the second slit is effectively elimnated from reaching the exit slit by the use of the second spectrometer provided on this instrument. 
The instrument operates with a single wavelength control. Spectral bands transmitted by the slits were comparable in width $(\mathrm{m} \mu)$ to those obtained with the photographic method. A photoelectric cell of the electron-emission type was used as detector and values of spectral transmittancy were obtained by means of the ratio-of-deflections method with a high-sensitivity galvanometer.

The scale for reading or setting wavelengths on this monochromator is a linear one (not direct reading in millimicrons) and a wavelength calibration curve of the instrument was already available. ${ }^{6}$ This curve was based upon scalar settings previously determined for mercury lines down to $237.8 \mathrm{~m} \mu$. As the incandescent lamp was the only source of irradiation for the spectrophotometric work, the wavelength calibration was frequently checked at one wavelength $(557 \mathrm{~m} \mu)$ by means of two particular standard glasses whose spectral transmittances are known to be the same at that wavelength. The linear correction determined at this wavelength was then applied to the whole scale.

The lower end of the wavelength calibration curve was extrapolated below $237.8 \mathrm{~m} \mu$ for these measurements, and the data in this region with the Brackett instrument are therefore of lesser validity.

\section{b. General Electric Recording Spectrophotometer}

The General Electric recording spectrophotometer has been described in a series of three papers [16, $17,18]$. The data obtained with this instrument are for the visible range only and extend from 400 to $750 \mathrm{~m} \mu$. Checks on the wavelength scale were made in the usual manner by using a calibrated didymium glass. A nominal slit width equivalent to approximately $4 \mathrm{~m} \mu$ was used throughout the recordings. Cells of $1.000-\mathrm{cm}$ thickness were used for the measurements.

\section{c. Beckman Quartz Spectrophotometer (Model DU)}

The Beckman spectrophotometer has been described in a paper by Cary and Beckman [19]. Transmission measurements with a modification of this instrument, which has a constant-temperature enclosure ${ }^{7}$ designed and constructed at the National Bureau of Standards, have been described in detail in a paper by Gibson and Balcom [20]. All measurements on the Beckman spectrophotometer were made with a $1.000-\mathrm{cm}$ cell. The cell holder is kept constant at $25^{\circ} \mathrm{C}$ or other desired temperature by means of water pumped through from a constant-temperature bath.

For wavelength checks the $\mathrm{Hg}$ green line (546.1 $\mathrm{m} \mu$ ) was used. When necessary, the whole wavelength scale was adjusted by the slight turning of

${ }^{6}$ Acknowledgment is here made to W. F. Roeser and M. S. Van Dusen for making the instrument and its calibration curve available.

\% In 1942 a few measurements on a Beckman quartz spectrophotometer in the Bureau's Chemistry Division were made on an alkaline solution prepared in 1940. No temperature control was available for these measurements. the internal screw that rotated the collimating mirror. After such check or adjustment, the precise wavelength correction was then applied at each wavelength setting in accordance with the curve illustrated in figure 6 of reference [20].

For transmittancy measurements three sources are available, namely, the incandescent-filament lamp, the hydrogen arc, and the mercury arc, all as supplied by the maker. The incandescent and hydrogen sources were used over the appropriate wavelength ranges, overlapping from 320 to $380 \mathrm{~m} \mu$. The slit widths with these sources never exceeded $2 \mathrm{~m} \mu$ and were usually less than $1 \mathrm{~m} \mu$. The mercury arc was also used for transmittancy measurements at certain wavelengths as noted below.

A clear quartz lens similar to that supplied with the instrument was used to effect an approximate collimation of the beam. Over the wavelength range from 330 to $420 \mathrm{~m} \mu$ with the incandescent source and from 360 to $380 \mathrm{~m} \mu$ with the hydrogen source, a purple (Corning filter No. 9863) lens was used to reduce stray light as well as to collimate the beam.

\section{Standard Spectrophotometric Data}

In examining the data obtained during the first two years of the investigation, the type $\mathrm{A}$, or alkaline, solutions were found to give more reproducible results (i. e., less scattering of data on repeated measurements) than the type B, or neutral, solutions. Furthermore, the alkaline solutions were found to give a better range of transmittancies in the extreme ultraviolet than the neutral solutions. Since the alkaline solutions were thus found to fulfill more nearly the requirements of a standard of spectral transmittancy in the ultraviolet, all later work and all the detailed data to be presented refer to the alkaline solution of potassium chromate $(0.04 \mathrm{~g}$ /liter in 0.05 $N \mathrm{KOH})$.

As already noted, the work on the 1940 and 1942 solutions was interrupted in 1943. Sufficient data were obtained, however, that a tentative set of spectral transmittancy values could be evaluated. These values are given ${ }^{8}$ in column 2 of table 1 , designated as $T_{s}^{\prime}$. They were read from a curve, of which figure 1 is a tracing. The individual determinations by the five instruments used are plotted and may be identified from the legend. These tentative values thus represent a graphical average of all these earlier data. Measurements were made on the 1940 solutions a few days after their preparation and then again at the end of $2,4,7,8$, and 10 months, 2 years 4 months, 2 years 5 months, and 2 years 7 months. The 1942 solutions were measured a few days after their preparation and again in 1,2 , and 6 months.

\footnotetext{
8 These tentative values have also been published in $[8 ; 9$, p. 43-44; 10, p. 261].
} 


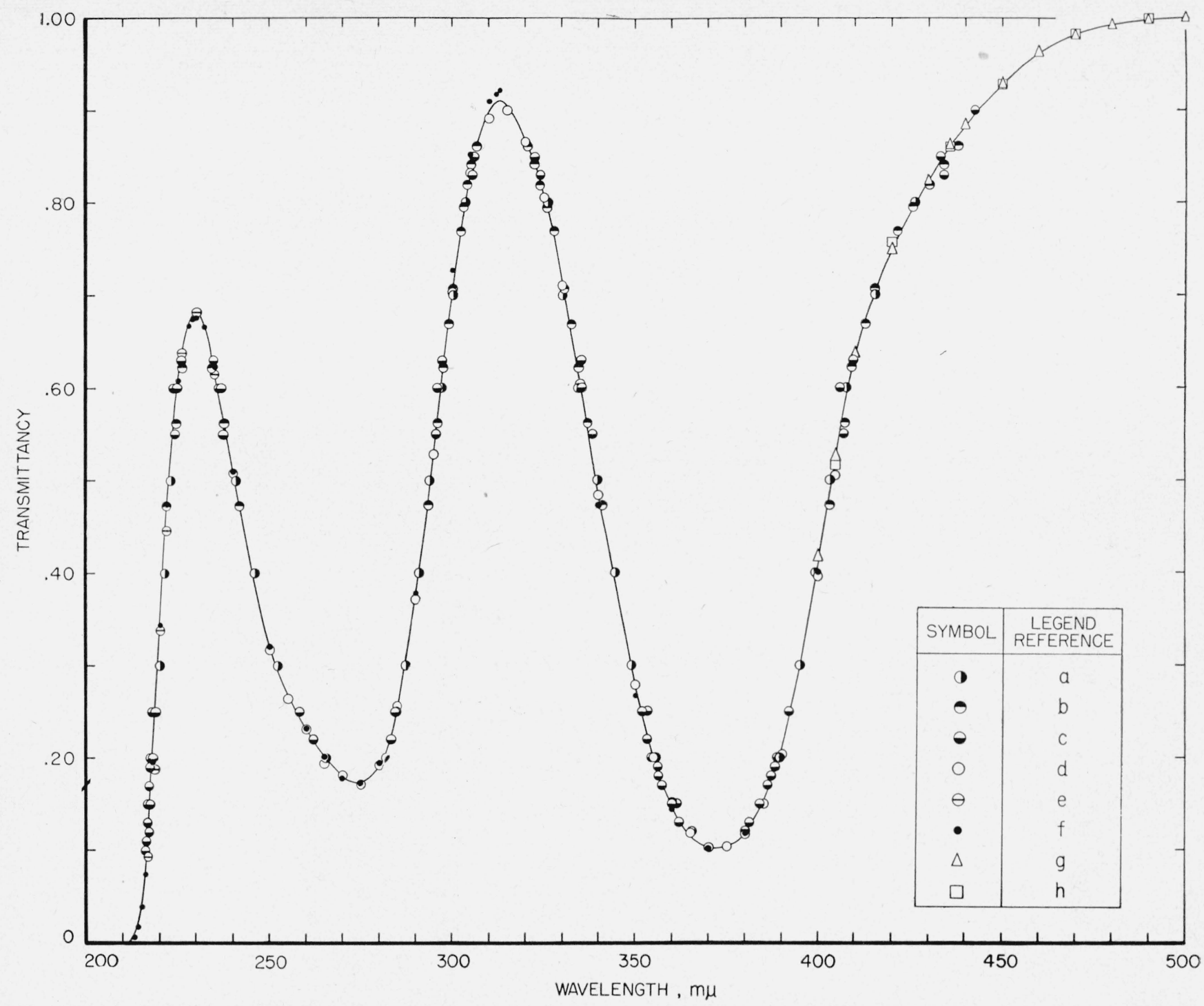

FIGURE 1. Tracing of original curve from which tentative values of spectral transmittancy, $T^{\prime}{ }_{s}$, were read (table 1 , column 2$)$ and published $[8,9,10]$ for potassium chromate solution $\left(0.0400 \mathrm{~g} /\right.$ liter of $\mathrm{K}_{2} \mathrm{CrO}_{4}$ in $\left.0.05 \mathrm{~N} \mathrm{KOH}\right)$

Distilled water only was used in the solvent cell. These data were obtained in 1940 and 1942, as follows:

\begin{tabular}{|c|c|c|c|c|c|}
\hline & Spectrophotometer & $\begin{array}{l}\text { Wavelength } \\
\text { range used }\end{array}$ & $\begin{array}{l}\text { Alkaline } \\
\text { solution } \\
\text { prepared }\end{array}$ & $\begin{array}{c}\text { Cell } \\
\text { length }\end{array}$ & $\begin{array}{l}\text { Number } \\
\text { of deter- } \\
\text { mina- } \\
\text { tions rep- } \\
\text { resented }\end{array}$ \\
\hline a & $\begin{array}{l}\text { Hilger sector photo- } \\
\text { meter (photograph- } \\
\text { ic). }\end{array}$ & $\begin{array}{c}m \mu \\
215 \text { to } 450 \ldots\end{array}$ & $\begin{array}{l}\mathrm{A}_{1}, 1940 \\
\mathrm{~A}_{2}, 1940\end{array}$ & $\begin{array}{r}\mathrm{cm} \\
1 \\
1\end{array}$ & \} 5 to 7 \\
\hline $\begin{array}{l}\mathrm{b} \\
\mathrm{c}\end{array}$ & & & $\begin{array}{r}\mathrm{A}_{1}, 1940 \\
\mathrm{~A}_{1}, 1940 \\
\mathrm{~A}_{2}, 1940 \\
1942\end{array}$ & $\begin{array}{l}4 \\
1 \\
1\end{array}$ & $\left\{\begin{array}{r}1 \\
1 \text { to } 3\end{array}\right.$ \\
\hline d & $\begin{array}{l}\text { Brackett double mono- } \\
\text { chromator (photo- } \\
\text { electric). }\end{array}$ & 240 to 404.7 - & $\begin{array}{r}\mathrm{A}_{1}, 1940 \\
1942 \\
\mathrm{~A}_{2}, 1940 \\
1942\end{array}$ & $\begin{array}{l}1 \\
1\end{array}$ & $\{2$ to 5 \\
\hline $\mathrm{f}$ & $\begin{array}{l}\text { Beckman (photoelec- } \\
\text { trie). }\end{array}$ & $\begin{array}{l}\text { Adjusted be- } \\
\text { low } 240 . \\
213 \text { to } 400\end{array}$ & $\begin{array}{l}\mathrm{A}_{1}, 1942 \\
\mathrm{~A}_{2}, 1942 \\
\mathrm{~A}_{1}, 1940\end{array}$ & $\begin{array}{l}1 \\
1 \\
1\end{array}$ & \} \\
\hline $\mathrm{g}$ & $\begin{array}{l}\text { GE automatic record- } \\
\text { ing (photoelectric). }\end{array}$ & 400 to $750 \ldots$ & $\begin{array}{l}\mathbf{A}_{1}, 1942 \\
\mathbf{A}_{2}, 1942\end{array}$ & $\begin{array}{l}1 \\
1\end{array}$ & \} \\
\hline $\mathrm{h}$ & $\begin{array}{l}\text { König-Martens (vis- } \\
\text { ual). }\end{array}$ & 404.7 to $600 \ldots$ & $\begin{array}{l}\mathrm{A}_{1}, 1940 \\
\mathrm{~A}_{2}, 1940\end{array}$ & $\begin{array}{r}4 \\
10\end{array}$ & $\{1$ to 4 \\
\hline
\end{tabular}


TARLE 1. Spectrophotometric data for a standard potassium chromate solution $(0.0400 \mathrm{~g} /$ liter in $0.05 \mathrm{~N} \mathrm{KOH})$, unfiltered, at $25^{\circ} \mathrm{C}$

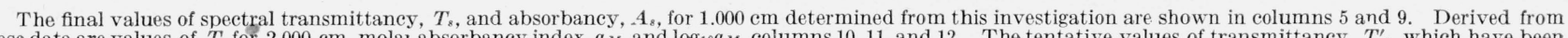

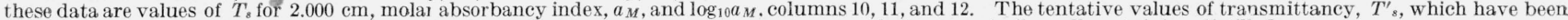
published $[8,9,10]$ were taken from column 2 . The solution was measured in every case relative to a similar cell containing distilled water.

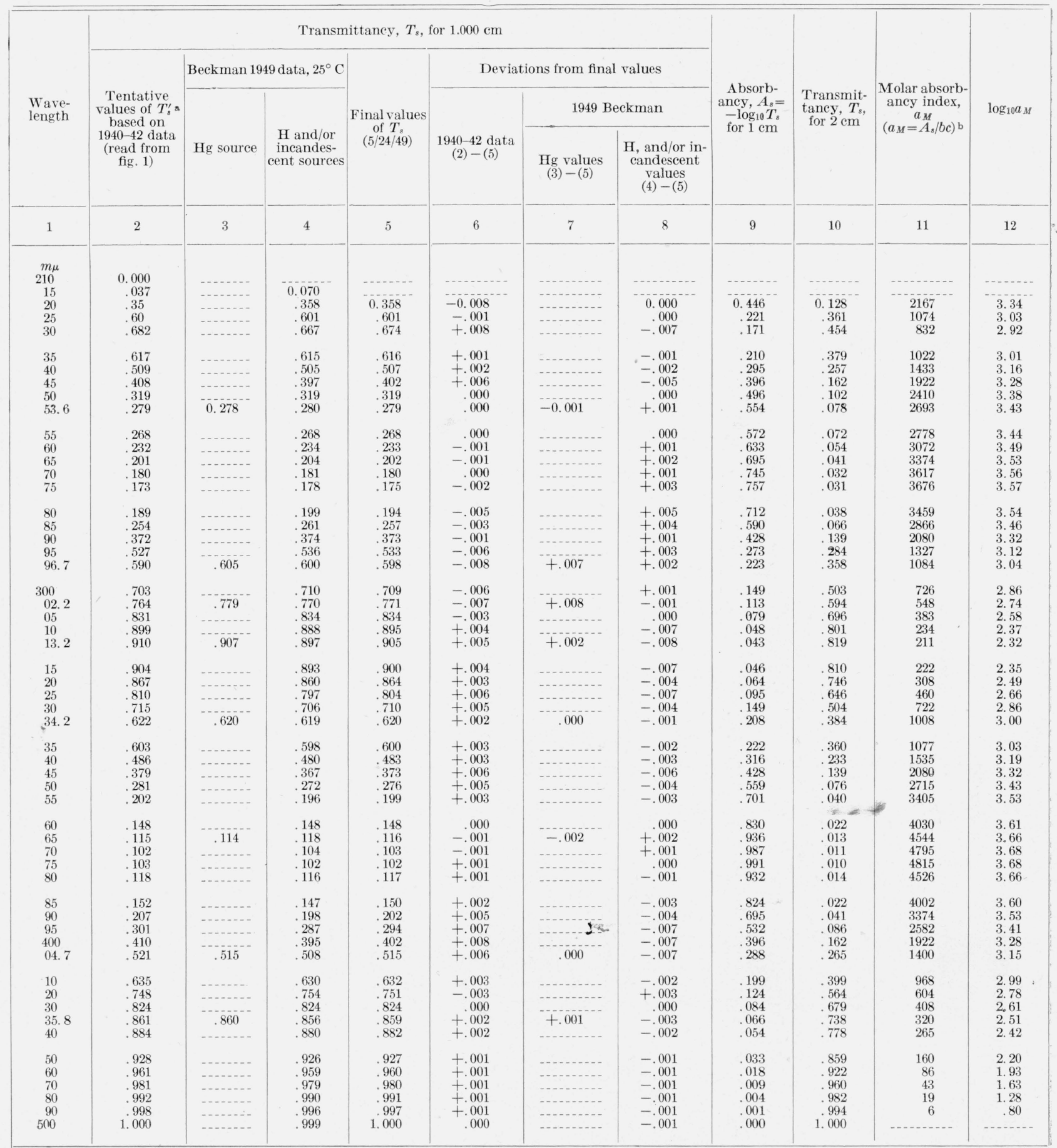

s These values were read from the original of figure 1 and are consistent with the values published later $[8,9,10]$. $\quad c=0.0002059 M ; b=1 \mathrm{~cm}$. 
In April 1949 four sets of data were taken on the Beckman spectrophotometer [20], one on each of freshly prepared alkaline $\left(A_{1}\right.$ and $\left.A_{2}\right)$ solutions maintained at $25^{\circ} \mathrm{C}$, stored both in glass and alkaliresistant ware.

The four sets of data were averaged. Values obtained with the mercury source are listed in column 3 of table 1 ; values obtained with the hydrogen and/or incandescent sources are listed in column 4.

The final values of $T_{s}$ shown in column 5 were derived according to the following procedures:

(a) At the mercury wavelengths, a straight average of three sets of data, namely, (1) 1949 Beckman data with mercury line source (column 3); (2) 1949 Beckman data with hydrogen and/or incandescent continuous-spectrum source (column 4); (3) Tentative values based on 1940-42 data, $T_{s}^{\prime}$, (column 2).

(b) At other wavelengths above $220 \mathrm{~m} \mu$ (with the exception of 295 to 315 ) a straight average of two sets of data, namely, (1) 1949 Beckman data with hydrogen and/or incandescent source (column 4); (2) Tentative values based on 1940-42 data, $T_{s}^{\prime}$ (column 2).

At $295,300,305,310$, and $315 \mathrm{~m} \mu$ slight further adjustments in $T_{s}$ (not exceeding 0.003 ) were made to bring the final values into better agreement with the averages obtained at the mercury wavelengths, using procedure (a).

Columns 6,7 , and 8 of table 1 show the deviations of the three sets of data from the final values. It is evident that there may be considerable uncertainty in the third decimal of column 5 .

Values of spectral absorbancy, $A_{s}$, for a $1.000-\mathrm{cm}$ thickness of solution are given in column 9. These values of $A_{s}$ were derived from the relation $A_{s}=-\log _{10} T_{s}$. To cover the photometric scale below $T_{s}=0.10$, values of transmittancy for a $2.000-\mathrm{cm}$ cell were computed and are given in column 10 .

Column 11 gives values of the molar-absorbancy index [21] $a_{M} \equiv A_{s} / b c$ where $c$ is the concentration expressed in moles per liter, and $b$ is the cell thickness in centimeters. Column 12 gives the values of $\log _{10} a_{M}$.

\section{Comparison of Data with Those of Other Observers}

Tabular data on the spectral transmittancy of potassium chromate in $0.05 \mathrm{~N}$ potassium hydroxide have been published by von Halban and Siedentopf [22], Rössler [23], Baly, Morton, and Riding [24], and Hogness, Zscheile, and Sidwell [25].

Hogness, Zscheile, and Sidwell used a photoelectric method for their determinations. The potassium chromate was recrystallized four and five times. They show the absorption spectrum for this solution in a figure [25]. The dots through which the curve is drawn in their figure are taken from several series of determinations at $2.5-\mathrm{m} \mu$ intervals from 220 to $410 \mathrm{~m} \mu$. Values of molar extinction for the maxima and minima and for 366 and $265 \mathrm{~m} \mu$ were given in tabular form. The experimental conditions under which these tabulated data were obtained are given in table 2 .
Figure 2 compares the present data with those already published in tabular form. $\log _{10} a_{M}$ is used for this comparison in accord with the practice used in the International Critical Tables [26]. The methods used in the various studies are shown in the caption.

TABLE 2. Experimental conditions under which certain data of Hogness, Zscheile, and Sidwell [25] were obtained

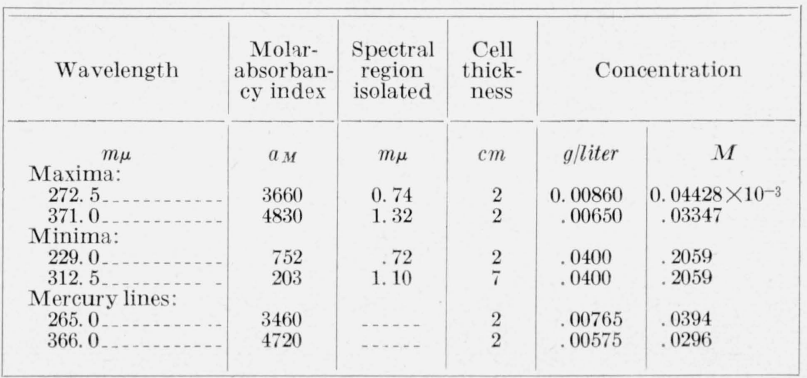

From figure 2 it may be seen that in general the agreement in $\log _{10} a_{M}$ from 220 to $450 \mathrm{~m} \mu$ found by the five investigators shown is quite close, with the exception of a few points. Below $300 \mathrm{~m} \mu$, two values of von Halban (photoelectric method) at 254 and $265 \mathrm{~m} \mu$ are at variance with the rest. Above 300 $\mathrm{m} \mu$, the value of Baly, Morton, and Riding (photographic method) at $313.2 \mathrm{~m} \mu$, seems erroneous. Most of the 16 wavelength values of Rössler from 381.5 to $439.0 \mathrm{~m} \mu$ will be seen to be lower in $\log _{10} a_{M}$ than those of the others shown. In his paper, Rössler has put these wavelengths in parentheses; apparently these were so indicated because of the relatively low dispersion of the prism in his instrument.

In the present investigation only a single concentration of potassium chromate was used. No attempt was made to carry out a study of conformity to Beer's law, because the one solution in 1- and 2 -cm thicknesses covered the photometric range of interest. However, it was known that Hogness, Zscheile, and Sidwell had made a run on exactly the same concentration used by von Halban and found good agreement with their curve [25] obtained from data on optimum concentration. From these data it was concluded that Beer's law held. Results have also been published [27] of Beer's law tests on potassium chromate in $0.05 \mathrm{~K} \mathrm{KOH}$ at $372 \mathrm{~m} \mu$. Various dilutions were used, and the results are given in both tabular and graphical forms. The molecular concentrations used varied from $1.61 \times 10^{-5}$ to $51.5 \times$ $10^{-5}$. This corresponds to variations in concentration from 0.00313 to $0.1000 \mathrm{~g}$ /liter. Determination of this compliance with Beer's law was made as a means of checking the photometric reproducibility of a new spectrophotometer.

\section{Effect of Temperature on Spectral Transmittancy}

Because it was desirable to know whether or not the potassium chromate solution for use as a calibration standard changed in spectral transmittancy 


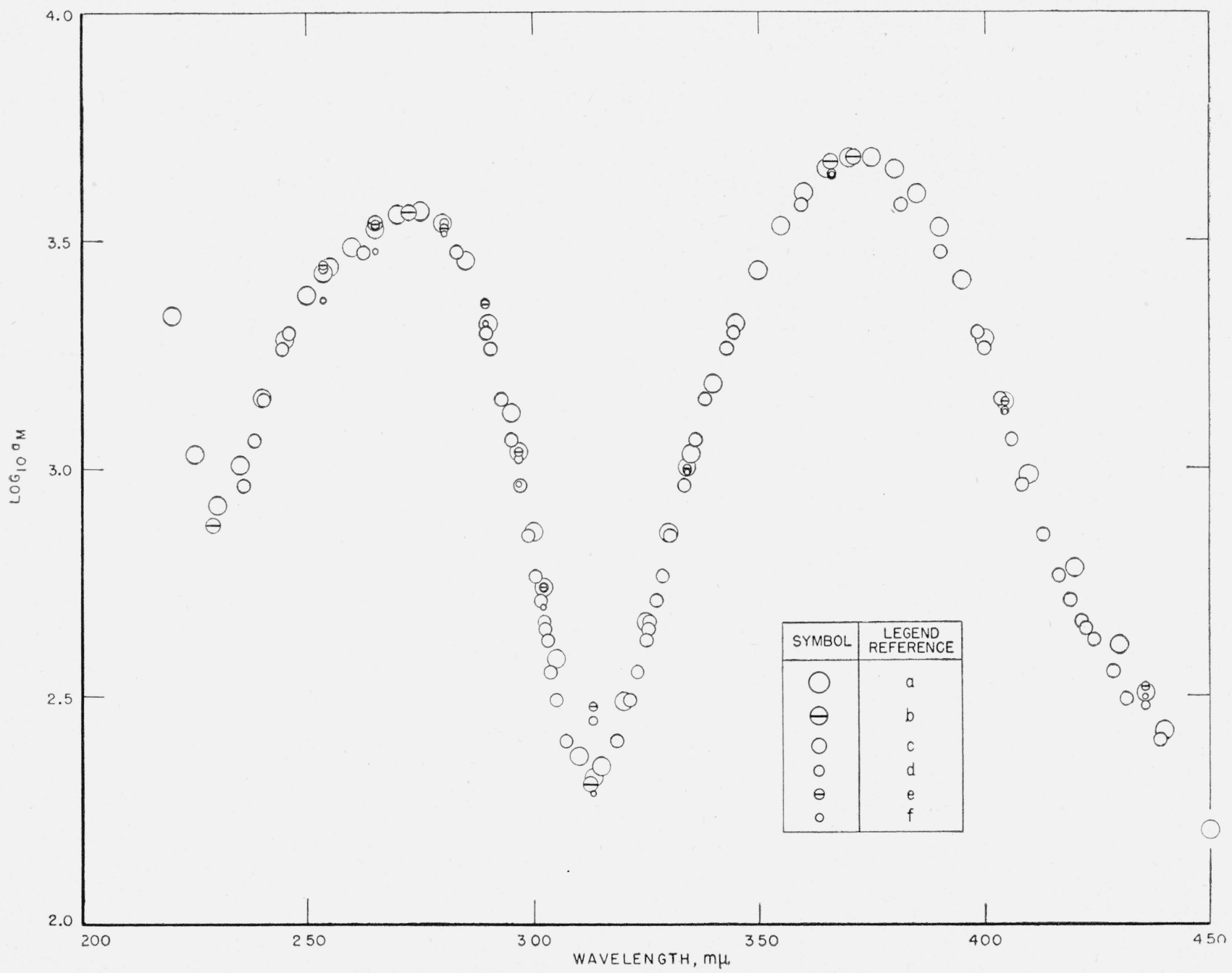

Figure 2. Values of $\log _{10} a_{M}$ for potassium chromate.

Molar solution in $0.05 N$ KOH. $b=1 \mathrm{~cm} ; a_{M}=A_{s} / \mathrm{bc}=-\log _{10} T_{s} / b c$

a. From NBS final data, column 12 of table 1.

b. Hogness, Zscheile, Sidwell; photoelectric

c. Rössler; photographic.

d. Baly, Morton, and Riding-Hilger rotating sector; photographic

e. Baly, Morton, and Riding Judd-Lewis sector; photographic.

f. von Halban; photoelectric.

with change in temperature, several preliminary tests were made in 1948 on the 1942 solutions by means of the Beckman spectrophotometer [20]. The resulting data indicated that the largest effects due to changes in temperature occur below $235 \mathrm{~m} \mu$.

A more detailed and complete study of the change in spectral transmittancy with temperature was then made for the 1949 alkaline solutions of both types stored in alkali-resistant bottles. The wavelength range from 215 to $500 \mathrm{~m} \mu$ was studied for approximately a 25-deg change in temperature. The spectral-transmittancy data were determined for one solution over a definite wavelength range at $25^{\circ}, 50^{\circ}$, and again at $25^{\circ} \mathrm{C}$ in a single day. Each change in spectral transmittancy for an approximately 25deg change in temperature was computed separately for each day's set of measurements. Three sets were averaged and are plotted in large circles in figure 3 .

Included in the figure are also points obtained from the measurements made on the 1942 alkaline solutions at various times at each of the temperatures, $25^{\circ}$ and $50^{\circ} \mathrm{C}$. These data corroborate the data obtained with the 1949 solutions. It may be of interest to point out that the changes in transmittancy with increase in temperature shown in figure 3 are such as to indicate a shift of the absorption bands toward longer wavelengths.

The curve shown in figure 3 was then drawn, from which values of $\Delta T_{s}$ for a change of $25 \mathrm{deg}$ were read. Values of $\Delta T_{s}$ for a change of 10 deg were computed from these curve readings by linear interpolation, and the resulting data are given in table 3 . Users of the standard solution should 


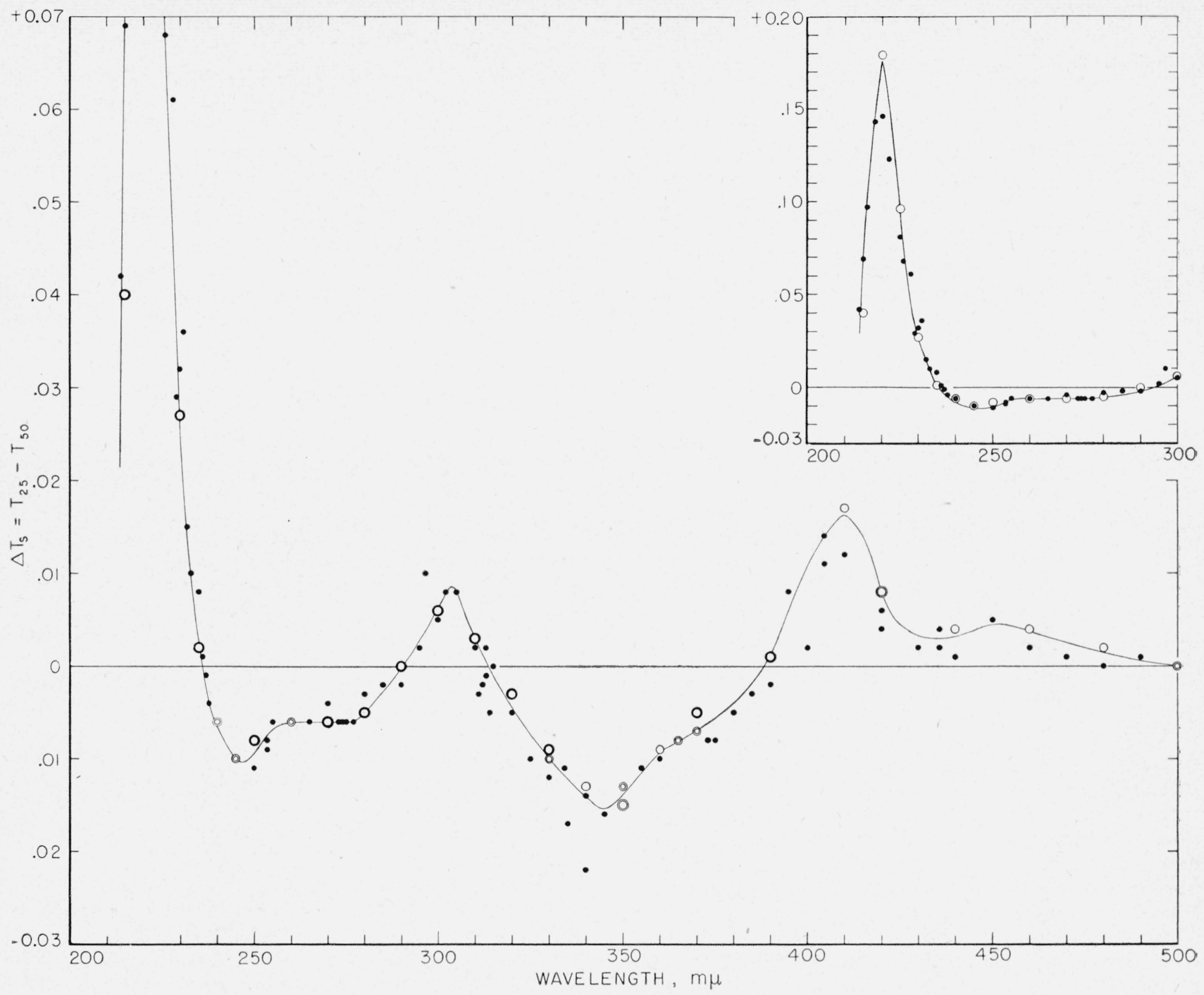

Figure 3. Change in spectral transmittancy for a change in temperature of $25^{\circ} \mathrm{C}$.

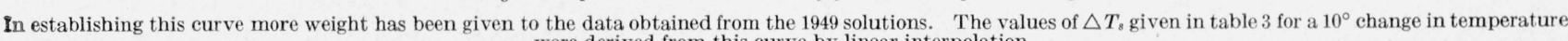
were derived from this curve by linear interpolation.

О, $\triangle T_{s}\left(=T_{25}-T_{50}\right)$ for 1949 solutions. (The measurements were all made on the same day.)

, $\triangle T_{s}$ for 1942 solutions. (The measurements were made in 1948, mostly on different days.)

make use of these corrections proportionately whenever the temperature of the solution deviates importantly from $25^{\circ} \mathrm{C}$. Values of $\Delta A_{s}$ in table 3 are derived from the values of $\Delta T_{s}$ by the relation.

$$
\Delta A_{s}=-\log _{10} e \frac{\Delta T_{s}}{T_{s(\mathrm{avg})}} .
$$

\section{Permanence}

Measurements have been made from time to time on these alkaline solutions, and the study has included effects due to the storage of some of the solutions over periods up to 8 years. The 1940 alkaline solution made from $\mathrm{K}_{2} \mathrm{CrO}_{4}$ in $\mathrm{KOH}$ was stored both in an ordinary glass bottle and in a similar bottle lined with ceresin. The 1940 alkaline solution made from $\mathrm{K}_{2} \mathrm{Cr}_{2} \mathrm{O}_{7}$ and the 1942 alkaline solutions made both from chromate and dichromate were stored only in ordinary glass bottles.

Above $260 \mathrm{~m} \mu$ no definite change in spectral transmittancy was found for the solutions stored in glass. Below $260 \mathrm{~m} \mu$ the 1940 alkaline solutions showed definite changes at the end of 8 years of storage in glass bottles, the solution made from the dichromate exhibiting the smaller change. The fact that potassium dichromate in stock material exists in a purer state may account for this solution being more stable. However, the 1942 alkaline solutions of both types likewise stored in glass bottles showed little if any change in spectral transmittancy over a period of 6 years. 
TABLE 3. Values of $\Delta T_{s}\left(=T_{25}-T_{35}\right.$ or $\left.T_{15}-T_{25}\right)$ for a $10^{\circ} \mathrm{C}$ change in temperature corresponding to wavelengths listed

These values are for a cell length of $1.000 \mathrm{~cm}$ and are two-fifths of the values read from the curve of figure 3 . Values of $\Delta A_{s}$ are derived from the values of $\Delta T_{s}$.

\begin{tabular}{|c|c|c|c|c|c|}
\hline $\begin{array}{l}\text { Wave- } \\
\text { length }\end{array}$ & $\begin{array}{l}\text { Values of } \\
\Delta T_{s} \text { for } \\
10 \mathrm{deg} . \mathrm{C}\end{array}$ & $\begin{array}{l}\text { Values of } \\
\Delta A_{s} \text { for } \\
10 \mathrm{deg} . \mathrm{C}\end{array}$ & $\begin{array}{l}\text { Wave- } \\
\text { length }\end{array}$ & $\begin{array}{l}\text { Values of } \\
\Delta T_{s} \text { for } \\
10 \mathrm{deg} \text {. C }\end{array}$ & $\begin{array}{l}\text { Values of } \\
\Delta A_{s} \text { for } \\
10 \mathrm{deg} . \mathrm{C}\end{array}$ \\
\hline$m_{\mu}$ & & & $m_{\mu}$ & & \\
\hline 210 & & & 330 & .0040 & .0024 \\
\hline 15 & +0.028 & -0.22 & 34.2 & .0047 & .0033 \\
\hline 20 & .070 & .094 & & & \\
\hline $\begin{array}{l}20 \\
30\end{array}$ & $\begin{array}{l}.035 \\
.0100\end{array}$ & $\begin{array}{l}.026 \\
.0065\end{array}$ & $\begin{array}{l}35 \\
40\end{array}$ & $\begin{array}{l}.0049 \\
.0056\end{array}$ & $\begin{array}{l}.0035 \\
.0050\end{array}$ \\
\hline & & & 45 & .00022 & .0072 \\
\hline 35 & +.0010 & -.0007 & 50 & .0056 & .0087 \\
\hline 40 & -.0026 & +.0022 & 55 & .0046 & .0099 \\
\hline 45 & .0040 & .0043 & & & \\
\hline 50 & .0038 & .0051 & 60 & .0037 & .0107 \\
\hline 53.6 & .0030 & .0046 & $\begin{array}{l}65 \\
70\end{array}$ & $\begin{array}{l}.0033 \\
.0028\end{array}$ & $\begin{array}{l}.0122 \\
.0116\end{array}$ \\
\hline 55 & .0027 & .0044 & 75 & .0022 & .0093 \\
\hline 60 & .0024 & .0045 & 80 & .0016 & .0059 \\
\hline 65 & .0024 & .0051 & & & \\
\hline 70 & .0024 & .0058 & 85 & -.0007 & +.0020 \\
\hline 75 & .0024 & .0059 & $\begin{array}{l}90 \\
95\end{array}$ & $\begin{array}{r}+.0005 \\
.0024\end{array}$ & $\begin{array}{r}-.0011 \\
.0036\end{array}$ \\
\hline 80 & .0020 & .0045 & 400 & .0043 & .0047 \\
\hline 85 & .0011 & .0019 & 04.7 & .0056 & .0047 \\
\hline 90 & -.0001 & +.0001 & & & \\
\hline 95 & +.0011 & -.0009 & 10 & .0065 & .0045 \\
\hline 96.7 & .0016 & .0012 & $\begin{array}{l}20 \\
30\end{array}$ & $\begin{array}{r}.0032 \\
.0013\end{array}$ & .0019 \\
\hline 300 & .0025 & .0015 & 35.8 & .0012 & .0006 \\
\hline 02.2 & .0031 & .0017 & 40 & .0013 & .0006 \\
\hline 05 & .0032 & .0017 & & & \\
\hline 10 & .0012 & -.0006 & 50 & .0018 & .0008 \\
\hline 13.2 & +.0001 & .0000 & 60 & .0015 & .0007 \\
\hline & & & 70 & .0010 & .0004 \\
\hline 15 & -.0004 & +.0002 & 80 & .0006 & .0003 \\
\hline 20 & .0018 & .0009 & 90 & +.0002 & -.0001 \\
\hline 25 & .0030 & .0016 & 500 & .0000 & .0000 \\
\hline
\end{tabular}

For the 1940 alkaline solution made from $\mathrm{K}_{2} \mathrm{CrO}_{4}$ in $\mathrm{KOH}$ and stored in a ceresin-lined bottle, measurements from time to time showed that changes in absorption were occurring. Data obtained at the end of an 8-year period showed that complete absorption had occurred below $370 \mathrm{~m} \mu$. Obviously, therefore, an ordinary glass bottle is better for storage of a solution of potassium chromate in $\mathrm{KOH}$ than a ceresin-lined bottle. No study of the permanence of the alkaline solutions stored in alkaliresistant bottles has been made.

It must also be concluded from this study that since the data below $260 \mathrm{~m} \mu$ show possibility of a change in spectral transmittancy after a 6-month period, solutions no older than 6 months should be used for the photometric calibration of a spectrophotometer in this region of the spectrum. On the other hand, for regions above $260 \mathrm{~m} \mu$, it seems safe to use alkaline solutions of either type stored in ordinary glass bottles up to a period of 5 years.

\section{Neutral Aqueous Solutions of Potassium Chromate}

Considerable data were obtained on the B solutions (see section 2) and a summary is presented here.

The spectral-transmittancy curve of neutral solutions of potassium chromate was found by Hantzsch [28] to differ somewhat from the alkaline solution, and the results reported here corroborate this finding. From 400 to $500 \mathrm{~m} \mu$ the curve for the neutral solution is less steep than that of the alkaline solution with a crossing point at about $440 \mathrm{~m} \mu$, above which the transmittancy of the alkaline solution is slightly higher. Between 300 and $330 \mathrm{~m} \mu$ the neutral solution is slightly lower in transmittancy than the alkaline solution and slightly higher both below and above this range up to $440 \mathrm{~m} \mu$. Below $230 \mathrm{~m} \mu$ this difference is large, the transmittancy at $215 \mathrm{~m} \mu$ being 0.40 for the neutral solution and 0.07 for the alkaline. The value $(0.07)$ for this wavelength may be found in table 1, column 4. More weight should be given the 1949 Beckman data below $225 \mathrm{~m} \mu$, because the measurements were obtained under closely controlled conditions of temperature and while the solutions were still fresh, two important controls for this particular region (sections 6 and 7 ). However, this particular value may be somewhat in error due to another cause, namely, the possible presence of impurities in the $\mathrm{KOH}$.

Over a period of years the neutral solutions were found to be more permanent than the alkaline solutions. Significant changes from 8-year storage in a glass bottle were confined to the spectral region below $230 \mathrm{~m} \mu$; and for storage in a ceresin-lined bottle changes were found only below $260 \mathrm{~m} \mu$. A specially pure sample (recrystallized four times) changed still less. The neutral solutions did not cause flaking in the bottles as the alkaline solutions do.

From the standpoint of permanence and convenience in storage the neutral solutions are slightly superior to the alkaline solutions, and had they been found equally reproducible the neutral solutions might be preferable as spectral transmittancy standards instead of the alkaline solutions.

\section{Summary}

Spectrophotometric studies of neutral and alkaline aqueous solutions of potassium chromate extending over a period of years have shown that the alkaline solution is the better suited for use as a spectraltransmittancy standard in the ultraviolet. The spectral transmittancy of this solution has been determined by five spectrophotometers used according to three different methods, and the final values are given in table 1 from 220 to $500 \mathrm{~m} \mu$. The final results are also expressed there in terms of absorbancy, $A_{s}=-\log _{10} T_{s}$, for a $1-\mathrm{cm}$ cell; molar absorbancy index, $a_{M}=A_{s} / b c$; and $\log _{10} a_{M}$. Changes of transmittancy with temperature were evaluated, and correction data for deviations from the standard temperature of $25^{\circ} \mathrm{C}$ are given in table 3 .

When stored in ordinary glass bottles, the solution is reasonably stable for 5 or 6 years. For work of the highest precision, however, to avoid unsuspected errors from any cause, it is recommended that solutions not over 6 months old prepared from chemicals of the highest purity be used as transmittancy standards.

\section{References}

[1] K. S. Gibson; Geraldine K. Walker, and Mabel E. Brown, Filters for testing the reliability of spectrophotometers, J. Opt. Soc. Am. 24, 58 (1934).

[2] Kasson S. Gibson and Marion A. Belknap, Permanence of glass standards of spectral transmittance, J. Research NBS 44, 463 (1950) RP2093. 
[3] W. W. Coblentz and R. Stair, Data on ultraviolet solar radiation and the solarization of window materials, BS J. Research 3, 629 (1929) RP113.

[4] W. W. Coblentz and R. Stair, Ultraviolet transmission changes in glass as a function of the wavelength of the radiation stimulus, BS J. Research 13, 773 (1934) RP744.

[5] Wallace R. Brode, Chemical spectroscopy, 2d ed. (John Wiley \& Sons, Inc., 1945).

[6] Photoelectric Spectrometry Group Bulletin No. 4 (J. A. Breckall \& Sons, Liverpool, 1951).

[7] Raymond Davis and K. S. Gibson, Filters for the reproduction of sunlight and daylight and the determination of color temperature, Misc. Pub. NBS 114 (1931).

[8] Standards for checking the calibration of spectrophotometers (200 to 1,000 $\mathrm{m} \mu$ ), Letter Circular NBS 929 (1948)

[9] K. S. Gibson, Spectrophotometry (200 to 1,000 millimicrons), Circ. NBS 484 (1949).

[10] Analytical absorption spectroscopy, edited by M. G. Mellon (John Wiley \& Sons, Inc., 1950).

[11] K. S. Gibson, H. J. MeNicholas, E. P. T. Tyndall, and M. K. Frehafer with the cooperation of W. E. Mathewson, Bureau of Chemistry. The spectral transmissive properties of dyes, I. Seven permitted food dyes in the visible, ultraviolet, and near infrared, Sci. Pap. BS 18, $121(1922-23)$ S 440.

[12] H. J. McNicholas, Use of the under-water spark with the Hilger sector photometer in ultraviolet spectrophotometry, BS J. Research 1, 939 (1928) RP33.

[13] K. S. Gibson, Spectrophotometry at the Bureau of Standards, J. Opt. Soc. Am. 21, 564 (1931).

[14] H. J. McNicholas, Equipment for routine spectral transmission and reflection measurements, BS J. Research 1, 793 (1928) RP30.

[15] F. S. Brackett, H. T. Wensel, and J. B. H. Kuper, Quartz double monochromator with single wavelength control, Phys. Rev. 5\%, 1059 (1940).

[16] A. C. Hardy, History of the design of the recording spectrophotometer, J. Opt. Soc. Am. 28, 360 (1938).
[17] J. L. Michaelson, Construction of the General Electric recording spectrophotometer, J. Opt. Soc. Am. 28, 365 (1938)

[18] K. S. Gibson and H. J. Keegan, Calibration and operation of the General Electric recording spectrophotometer of the National Bureau of Standards, J. Opt. Soc. Am. 28, 372 (1938).

[19] H. H. Cary and A. O. Beckman, A quartz photoelectric spectrophotometer, J. Opt. Soc. Am. 31, 682 (1941).

[20] K. S. Gibson and Margaret M. Balcom, Transmission measurements with the Beckman quartz spectrophotometer, J. Research NBS 38, 601 (1947) RP1798.

[21] Terminology and symbols for use in ultraviolet, visible, and infrared absorptometry, Letter Circular NBS 857 (1947).

[22] H. von Halban and K. Siedentopf, U̇ber die Verwendung von photoelektrischen zellen zur Messung der Lichtabsorption in Lösungen II, Z. physik. Chem. 100, 208 (1922).

[23] G. Rössler, Bemerkungen zur Technik der photographischen Spectrophotometrie, Ber. chem. Ges. 59, 2606 (1926)

[24] E. C. C. Baly, R. A. Morton, and R. W. Riding, The measurement of absorptive power, Proc. Roy. Soc. [A] 113, 709 (1926).

[25] T. R. Hogness, F. P. Zscheile, and A. E. Sidwell, Photoelectric Spectrophotometry-An apparatus for the ultraviolet and visible spectral regions: Its construction, calibration, and application to chemical problems, J. Phys. Chem. 41, 379 (1937).

[26] International Critical Tables V, 330 (McGraw-Hill Book Co., Inc., New York, N. Y., 1929) (see fig. 4).

[27] W. C. Miller, G. Hare, D. C. Strain, K. P. George, M. E. Stickney, and A. O. Beckman, A new spectrophotometer employing a glass Fery prism, J. Opt. Soc. Am. 39, 377 (1949).

[28] A. Hantzsch, Optische Untersuchungen über die Chromophore farbiger Salze und Säuren, Z. physik. Chem. 72, 362 (1910).

Washington, April 2, 1952. 